\title{
Utilization of Active Distribution Network Elements for Optimization of a Distribution Network Operation
}

\author{
Nevena Srećković ${ }^{1 * *(1)}$, Miran Rošer $^{2}$ and Gorazd Štumberger $^{1}$ (i) \\ 1 Faculty of Electrical Engineering and Computer Science, University of Maribor, Koroška Cesta 46, \\ 2000 Maribor, Slovenia; gorazd.stumberger@um.si \\ 2 Elektro Celje, d.d., Vrunčeva ulica 2a, 3000 Celje, Slovenia; Miran.Roser@elektro-celje.si \\ * Correspondence: nevena.sreckovic@um.si; Tel.: +386-2-220-7056
}

Citation: Srećković, N.; Rošer, M.; Štumberger, G. Utilization of Active Distribution Network Elements for Optimization of a Distribution Network Operation. Energies 2021, 14, 3494. https://doi.org/10.3390/ en14123494

Academic Editor: Emilio

Gomez-Lazaro

Received: 15 April 2021

Accepted: 9 June 2021

Published: 12 June 2021

Publisher's Note: MDPI stays neutral with regard to jurisdictional claims in published maps and institutional affiliations.

Copyright: (c) 2021 by the authors. Licensee MDPI, Basel, Switzerland. This article is an open access article distributed under the terms and conditions of the Creative Commons Attribution (CC BY) license (https:// creativecommons.org/licenses/by/ $4.0 /)$.

\begin{abstract}
Electricity Distributions Networks (DNs) are changing from a once passive to an active electric power system element. This change, driven by several European Commission Directives and Regulations in the energy sector prompts the proliferated integration of new network elements, which can actively participate in network operations if adequately utilized. This paper addresses the possibility of using these active DN elements for optimization of a time-discrete network operation in terms of minimization of power losses while ensuring other operational constraints (i.e., voltage profiles and line currents). The active elements considered within the proposed optimization procedure are distributed generation units, capable of reactive power provision; remotely controlled switches for changing the network configuration; and an on-load tap changer-equipped substation, supplying the network. The proposed procedure was tested on a model of an actual medium voltage DN. The results showed that simultaneous consideration of these active elements could reduce power losses at a considered point of operation while keeping the voltage profiles within the permitted interval. Furthermore, by performing a series of consecutive optimization procedures at a given time interval, an optimization of network operations for extended periods (e.g., days, months, or years) could also be achieved.
\end{abstract}

Keywords: active distribution network; active elements; reactive power provision; network reconfiguration; OLTC; minimization of losses

\section{Introduction}

The European Union is transitioning towards a low-carbon society, driven by Directives and Regulations in the energy sector concerned with the promotion of the use of energy from renewable sources, with common rules for the internal market of electricity, with risk-preparedness in the electricity sector, and with energy efficiency [1]. Novel requirements for Distribution Network (DN) operation, presented in the "Clean Energy for all Europeans" package [2], prompt the development and integration of new elements, an electricity market, and services. If an element of a network can be controlled, it is an active element. Otherwise, it is a passive element. The conventional methods of planning DNs, based only on deterministic, network solution planning, worst-case, and fit-and-forget methods, are considered obsolete and are being replaced by active planning approaches [3]. The consideration of active elements in these modern approaches should enable network operations and operations in extreme, still permissible conditions to have greater flexibility, which were previously not possible due to DN's passive nature.

Furthermore, a proliferated introduction of Advanced Measuring Infrastructure (AMI) aims to include system meters for all system users, a communication infrastructure that allows for data transmission from system counters to measuring centers and a single information system. If utilized and managed correctly, AMI should provide the input data necessary for advanced network operation, design, and optimization algorithms. 
This paper deals with the optimization of DN operations in terms of minimization of power losses at a considered point of operation by simultaneously determining the optimal settings of active elements present in the network. A decrease in the voltage level at which electricity is transferred through the network results in higher electric currents and higher power and energy losses. Therefore, reductions in power losses in Medium Voltage (MV) and Low Voltage (LV) parts of the electric power system are crucial for improving its performance. Furthermore, reducing power losses also reduces $\mathrm{CO}_{2}$ emissions and improves DN efficiency, which coincides with the "Clean Energy for all Europeans" package goals. The following literature review first provides an overview of the approaches to DN optimization. It then focuses on the procedures that consider active participation of reactive power provision, network configuration, and on-load tap change (OLTC) equipped substations. Finally, it presents the novelties and contributions of the proposed procedure by comparing it with similar approaches found in the literature.

Mathematical formulation and program implementation of various approaches to DN optimization differ significantly in terms of implementation reliability, complexity, and required computational effort, as certain techniques are more suitable for specific types of problems. A comprehensive review paper [4] describes DN optimization from the viewpoint of utilized optimization algorithms, including the selection of fitness functions and decision variables, loading models, size of the test networks, planning type, and planning period. This review concludes that, although various optimization algorithms have already been applied to various aspects of DN optimization problems, the development of efficient algorithms capable of escaping from local optima and finding near-global solutions remains an important issue. Sedghi et al. [5] outlined the main advantages of meta-heuristic algorithms for DN planning, compared to the classical, nowadays, considered outdated algorithms, such as the transportation [6] or branch and bound algorithms [7]. Within the metaheuristics, the authors of [5] distinguished between trajectory-based algorithms (e.g., branch exchange, simulated annealing, and tabu search) and population-based (e.g., genetic and evolutionary algorithms, ant colony, particle swarm optimization, and hybrid methods) and compared them. They concluded that the individual metaheuristics' capability depends on the dimension and complexity of the problem and finds that hybrid methods modified for specific problem solving show the most promising results, which is a similar conclusion to the one given in [8]. Additional literature surveys on the metaheuristic methodologies for minimization of power and energy losses are found in [4,9]. The papers compare different approaches, such as network reconfiguration, optimal installation of distributed generation (DG) units, their participation in reactive power provision, optimal placement of capacitor banks, optimal operation of tap-changer equipped substations, and demand response. Different approaches to solving a mixed-integer, nonlinear optimization problem for network reconfiguration aim to improve the computational efficiency and convergence characteristics and to reduce the possibility of selecting a local optimal solution. Examples of such approaches include simulated annealing [10,11], particle swarm optimization [12,13], evolutionary algorithms [14-16],fuzzy frameworks [17], and artificial neural networks $[18,19]$. Sultana et al. concluded that metaheuristic methods for network reconfiguration require fewer calculations and may converge to a final feasible solution quickly [20]. Although designed and built in a meshed topology, DN operates almost exclusively in a radial configuration [21]. The development of modern switching gears enabled more frequent changes in radial configuration, which could, provided AMI and proper algorithms, be utilized to optimize real-time operation [22]. Studies performed on real networks, considering fixed vs. hourly changes in network configurations [23,24], concluded that network reconfiguration results in a reduction in power losses. However, they emphasized caution when increasing the number of switching actions since these cause transient phenomena and reduce the devices' lifespan. Studies that also considered the presence of DG of constant [25] or variable power generation [22], and multi-criteria operation cost optimization [26] concluded that the benefits for the network outweigh the concerns mentioned above due to the volatile nature of DG. 
The optimal reactive power provision by DG units in the network can reduce the network's power losses [27-29] and shows excellent potential as an ancillary service provider [30]. Micro-inverters of photovoltaic (PV) systems result in greater network operation flexibility through optimal reactive power generation. However, the inverter's efficiency characteristics should be taken into account, as they are dependent on the amount of reactive power generated [31].

OLTC is a mechanical device that enables open-loop voltage control by varying the transformer turn ratio under load [32]. Once present only in primary distribution substations (DSSs), OLTC equipped transformers are nowadays also installed within secondary DSSs. Vacuum-type OLTCs require no scheduled maintenance in their lifetime (300,000 up to 600,000 tap operations, i.e., from 20 to 40 tap operations per day during a 40 year-long lifespan [32]), which makes them particularly suitable not only in the improvement of voltage profiles [33,34] but also in the reduction of network losses $[35,36]$. An example of the combined consideration of optimal reactive power provision and reduction in unnecessary tap operations also shows that minimization of power losses can be achieved while performing voltage control $[37,38]$. Although the approaches mentioned above offer specific solutions to optimizing various aspects of network operation, they lack the simultaneous consideration of active elements selected in the proposed procedure, with the objective to minimize power losses and to ensure operational constraints.

The procedure proposed in this paper is formulated as a nonlinear and constrained optimization problem, where the Differential Evolution (DE) algorithm [39] is used as the optimization tool. The active elements considered are DG units, capable of active participation in reactive power provision; remotely controlled switches for changing the network configuration; and an OLTC equipped substation, supplying the network. The search population, evaluated using a DE algorithm, finds optimal settings of these active elements, while constraints ensure proper ampacities of line segments and voltage profiles defined within EN 50160 [40]. Even though the same set of active elements can also be found in [41,42], their role in network operation, the optimization method, formulation of objective and constraint functions, and the type of test site considered are different. In our paper, the role of active elements in optimizing DN operation is the minimization of power losses while ensuring proper voltage profiles and line ampacities. Furthermore, our procedure is intended as a tool for online optimization of network operation, while the authors of [41] proposed a network planning tool and those of [42] offered a model for reactive power optimization. The IEEE 33-node network model was utilized in [41,42] while the proposed procedure was developed during the demo project on an actual DN to analyze the time-dependent role of installed active elements in minimizing power losses.

This paper simultaneously considers the active network elements in a network and gives them new roles in optimizing network operations through the proposed procedure. Therefore, the novelties and main contributions presented within the paper include the following:

- development of a computationally efficient and reliable optimization procedure for minimization of power losses at a considered point of operation using reactive power generation, network reconfiguration, and an OLTC equipped substation;

- at the same time, the procedure ensures proper voltage profiles and line ampacities;

- the procedure is scalable and flexible as it can be modified to include additional types of active elements and their increase in numbers;

- the procedure is intended to be used as a standalone tool for optimizing a single operation point or in a series of time-discrete optimization procedures in which long-term network operation is improved; and

- the procedure is intended to be easily implemented in real-world networks and to provide the proper measurement and communication infrastructure.

Improvement of a time-discrete and daily $\mathrm{DN}$ operation that can be achieved using the proposed procedure is demonstrated on a model of a real MV network. The considered network was a part of a smart grid demo project funded by Japanese technology agency 
NEDO and Slovenian Transmission system operator Eles d.o.o., implemented in Slovenian distribution networks.

The rest of the paper is structured as follows. The second section introduces and explains the proposed procedure for optimizing a DN operation through the utilization of active DN elements. The procedure is tested on a model of an actual MV DN through a case study presented in Section 3. The results obtained by implementing the procedure on the chosen test site are presented in Section 4, followed by the fifth section, which concludes the paper.

\section{Methodology}

A flowchart of the proposed procedure for optimization of a time-discrete DN operation using active elements is presented in Figure 1. The procedure comprises nine steps, marked (a)-(i) in Figure 1 for clarity purposes.

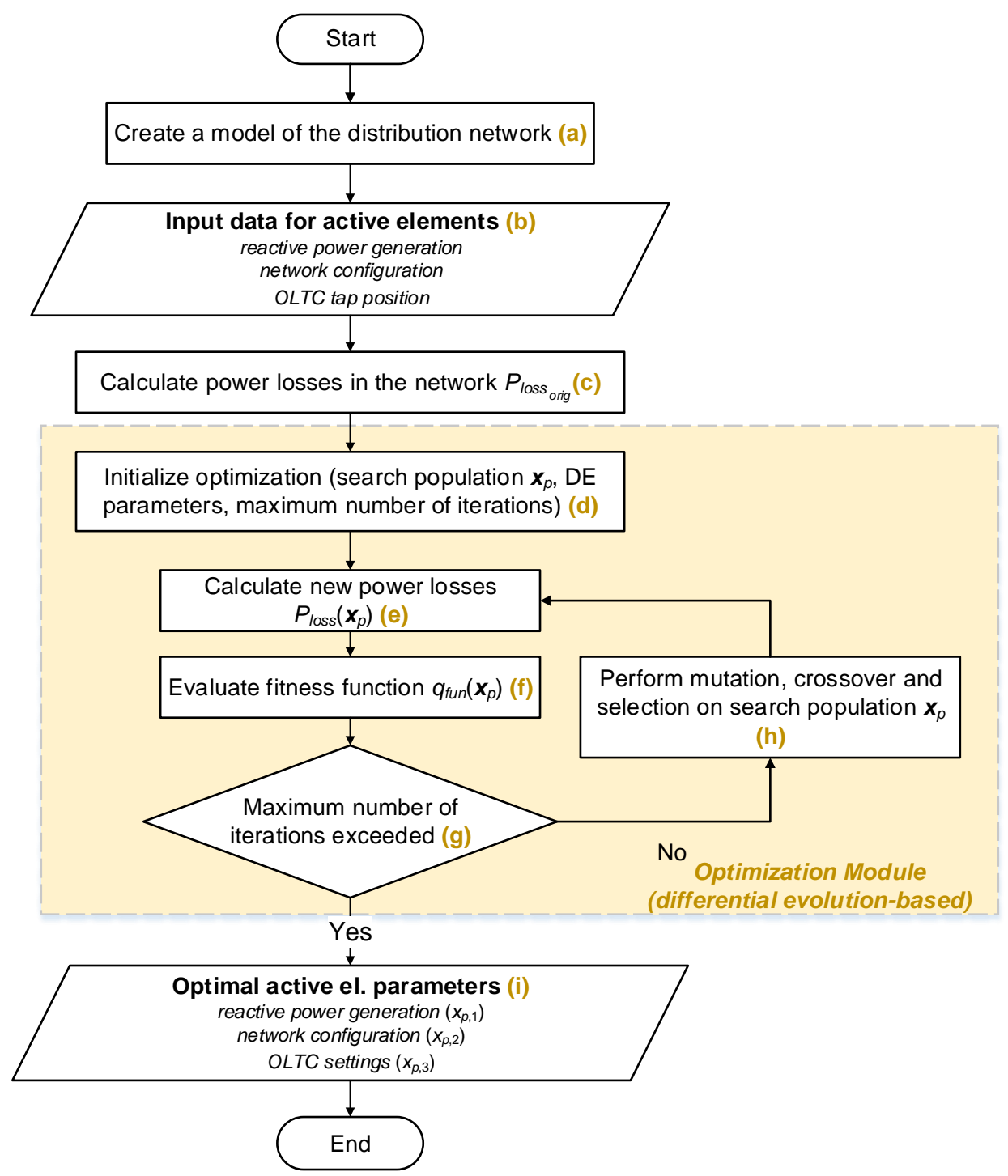

Figure 1. Flowchart of the proposed procedure for optimization of a network operation.

First, an evaluation of the operation state for the original network conditions is performed. Then, a detailed model of the considered network is created (step (a)). The initial settings of the considered active elements, i.e., the actual reactive power generation, network configuration, and OLTC's tap position at a considered time point and other loading and generation data, are provided in step (b). Based on these information, power losses for 
the original network conditions are calculated $\left(P_{\text {loss }}\right.$ orig $)$ using a backward-forward sweep method [43] for load flow calculation. From here, optimization of the procedure follows, i.e., the optimization module, which was implemented based on a DE algorithm [39]. The role of the optimization module is to find a vector of search parameters $x_{p}$ that minimizes the chosen fitness function $q_{f u n}$. In this paper, a vector of the search population defines the operational parameters, i.e., settings of the considered active elements, and their formulation is discussed in the following subsections. The optimization module comprises five steps, marked (d)-(h) in Figure 1. Step (d) includes the initialization of the vector of search population $x_{p}$ as well as the other optimization parameters, such as the maximum number of iterations, the crossover and mutation parameters, and the strategy for selection of new generations of a search population. For every vector of search population $x_{p}$ considered, the $\mathrm{DE}$ algorithm recalculates power losses (step (e)) and evaluates the corresponding value of the chosen fitness function $q_{f u n}$ (step (f)), with the goal of minimizing power losses while ensuring proper voltage profiles and preventing thermal overloading of power lines. The evaluation is performed until the maximum number of iterations is exceeded (step (g)). In the end, the optimization module returns the optimal settings of active elements (i.e., reactive power generation, network configuration, and tap position of the OLTC) for which the network operates with minimum losses (step (i)).

The fitness function $q_{f u n}$ is formulated with the objective to minimize the power losses in a time-discrete point, i.e., in the form of a quotient between the power losses of a currently evaluated solution $P_{\text {loss }}$ and losses of the initial network operation $P_{\text {loss }_{\text {orig }} \text {, }}$ as given in (1). During every evaluation of $q_{f u n}$ in step (f), penalty $p$ is applied if any of the defined constraints is violated, i.e., a search parameter not on a permitted interval $x_{p, i} \notin[0,1]$ or the occurrence of undervoltages, overvoltages, or thermal overloading.

$$
q_{f u n}\left(x_{p}\right)=\frac{P_{\text {loss }}\left(x_{p}\right)}{P_{\text {loss }_{\text {orig }}}}+p
$$

The vector of search parameters is a three-element vector $x_{p}=\left\{x_{p, 1}, x_{p, 2}, x_{p, 3}\right\}$. Parameter $x_{p, 1}$ searches for the optimal share of reactive power generation by DG units, the parameter $x_{p, 2}$ searches for the optimal network configuration, and parameter $x_{p, 3}$ searches for the optimal tap position of the OLTC equipped DSS supplying the network. DE, in its original formulation as given by its authors [39], searches for the optimal solution in a continuous space, i.e., in a set of real numbers $x_{p} \in \mathbb{R}$, usually on a normalized interval $x_{p} \in[0,1]$. However, network configuration and the tap position of OLTC are defined by discrete values and are selected from the set of positive integers $\mathbb{Z}^{+}$and a complete set of integers $\mathbb{Z}$, respectively. Therefore, some modifications of the original code, given by the authors of the DE [39], had to be made to allow for selection of the optimal network configuration and tap position from the set of integers. The idea of utilizing a DE for finding a solution that is not in a continuous space is not a new one, and different approaches to solving binary [44-46], or integer and mixed-integer differential evolution [47,48] can be found. The transition from a continuous to discrete search space, utilized for determining optimal network configuration and tap position, is discussed in Sections 2.2 and 2.3.

\subsection{Reactive Power Generation}

The optimal value of the first search parameter $x_{p, 1}$ determines such reactive power generation from the DG units integrated within the network, for which the network operates with minimum power losses. Its value is the same value for all DG units, thus ensuring reactive power generation impartiality between the individual units. Reactive power generation is defined as a relative share of active power generation on the interval $[-0.75,0.75]$. A positive sign represents the capacitive, and a negative sign represents the inductive nature of the generated reactive power. The maximum allowed share $( \pm 75 \%)$ is determined from [49], which states that DG units integrated within the network must operate with a power factor up to $\cos \varphi=0.8$. Using the phasor representation of a complex power in Figure 2, and basic relations between the amplitudes of its real component (active 
power) $P_{g e n}$ and imaginary component (reactive power) $Q_{g e n}$, the percentage (75\%) can be obtained by (2). A reactive power generation $Q_{g e n}$ in any observed time point is then defined as a share of active power generation $P_{\text {gen }}$ in the same instance, using the value of the search parameter $x_{p, 1}$ (3). The linear function $q\left(x_{p, 1}\right)$, which occurs in Figure 2 and (3), describes how the interval in which the independent variable is defined $x_{p, 1} \in[0,1]$ and translated into the dependent variable's interval $q \in[-0.75,0.75]$, as illustrated in the upper left corner in Figure 2.

$$
\begin{gathered}
Q_{\text {gen }}=P_{\text {gen }} \tan (\arccos 0.8)=0.75 P_{\text {gen }} \\
Q_{g e n}=q\left(x_{p, 1}\right) P_{g e n}=\left(1.5 x_{p, 1}-0.75\right) P_{g e n}
\end{gathered}
$$

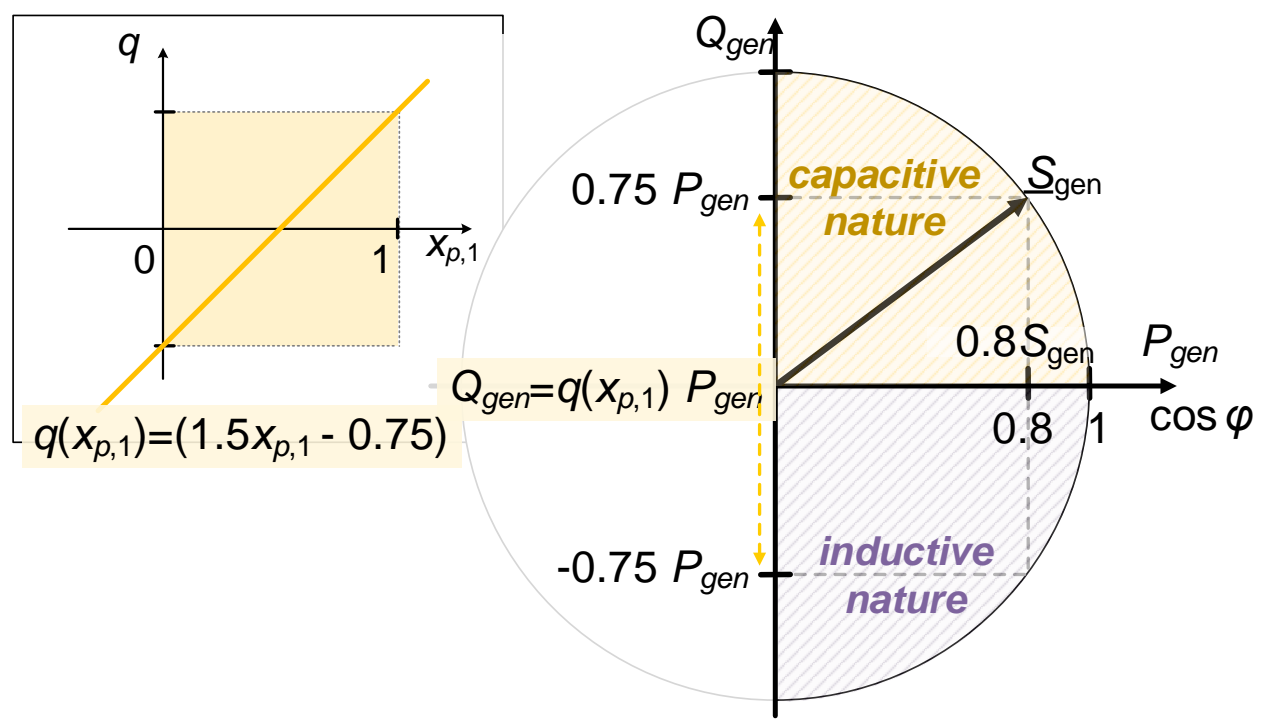

Figure 2. Phasor diagram of a complex power.

\subsection{Network Reconfiguration}

The second active element considered in this paper is a remotely controlled switch for changing the configuration in which the network operates. Its active participation in this paper is referred to as network reconfiguration. When appropriately utilized, the time-variant network reconfiguration can facilitate higher cost-effectiveness, efficiency, reliability, and power quality. However, some challenges remain in terms of network protection and stability [50,51].

In the proposed optimization algorithm, the second search parameter $x_{p, 2}$ is used for finding such a network configuration, which yields the minimum power loss at a considered operation point. The search parameter is defined on a normalized interval $x_{p, 2} \in[0,1]$. This search interval is then divided into $n_{\mathrm{CF}}$ subintervals, where $n_{\mathrm{CF}}$ equals the number of considered network configurations. Then, any value of $x_{p, 2}$ on the $i$ th subinterval corresponds to the $i$ th configuration, as presented in Figure 3 . For example, the first configuration $N_{C F}\{1\}$ is returned for $x_{p, 2}=\left[0, \frac{1}{n_{C F}}\right)$ and the second configuration $N_{C F}\{2\}$ is returned for $x_{p, 2}=\left[\frac{1}{n_{C F}}, \frac{2}{n_{C F}}\right)$, where vector $N_{C F}=\left\{1,2, \ldots, n_{C F}\right\}$ represents pointers to all possible network configurations. 


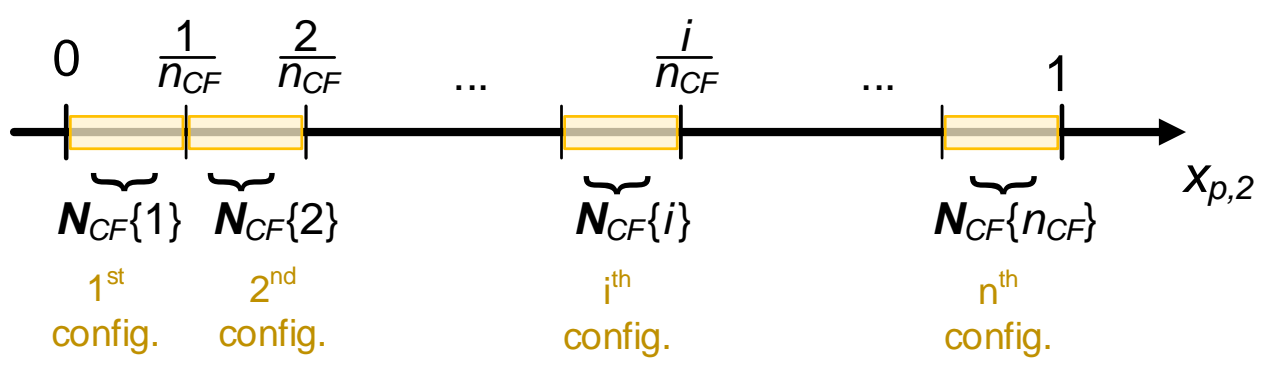

Figure 3. Discretization of a search space.

Index $N_{C F}$ of the radial configuration yielding minimum power losses represents an element of a vector of possible network configurations $N_{C F}$. It is determined from the value of search parameter $x_{p, 2}$, as given in (4). In other words, search parameter $x_{p, 2}$ is used in the calculation of a pointer to an individual network configuration $N_{C F}$. Even though the DE has to search for an optimal solution in discrete space, some of the nature of continuity is maintained by sorting the indices of radial configurations in the same order as the remotely controlled switches occur along the feeder. This way, opening consecutive switches along the line causes a gradual increase or decrease in power losses, as the network loads are transferred gradually from one feeder to another. Therefore, a proper ordering of indices in vector $N_{C F}$ plays an important role in preventing the local minima in which the DE may get stuck.

$$
N_{C F}=N_{C F}\left\{\left\lfloor x_{p, 2} \cdot n_{C F}\right\rfloor+1\right\}
$$

\subsection{Operation of OLTC}

An OLTC is a mechanical device installed inside a transformer tank or mounted in a separate compartment normally welded to the transformer. It enables voltage control by varying the transformer turn ratio under load without interruption in the electric energy supply. The change in turn ratio is performed by adding or subtracting turns from high- or low-voltage winding, using the control or tap winding connected to the OLTC. The voltage between the taps represents the step voltage $P_{\text {step }}$ [32]. The basic performance design of an OLTC, "make before break", allows for operation under load, as a resistor (or reactor) can connect two adjacent taps and can transfer the load from one tap to the other without supply interruption or a significant change in the load current. Simultaneously, they limit the circulating current for the period when both taps are used [32]. Advanced algorithms for active control of OLTC may be utilized to enable such an OLTC operation, which in addition to performing voltage control, can also minimize the power losses [52]. Similarly, the OLTC in this paper is utilized for both minimizing power losses and ensuring proper voltage profiles through given fitness and penalization functions, respectively.

An MV busbar of an OLTC equipped DSS supplying a network represents the slack node of a network model. The voltage amplitude $V_{1}$ of the slack node, for the tap positions $N_{\text {tap }} \in N_{\text {tap }}$, is determined using (5), with $V_{\text {baseMV }}$ being the base voltage of an MV part of the network.

$$
V_{1}=V_{\text {base } M V}+N_{\text {tap }} \frac{P_{\text {step }}}{100 \%} V_{\text {base } M V}
$$

The vector of possible tap positions $\boldsymbol{N}_{\text {tap }}$ is a symmetrical vector of negative and positive integers determined from the number of all tap positions for a considered OLTC device $n_{T C}$ using (6).The optimal tap position of OLTC $N_{\text {tap }} \in \mathbb{Z}$ is an integer number determined from the search parameter $x_{p, 3} \in[0,1]$. The problem of transition from a continuous to a discrete space is resolved by dividing the interval $x_{p, 3}$ into $n_{T C}$ subintervals as depicted in Figure 3, with each subinterval corresponding to an individual tap position. Parameter $x_{p, 3}$ plays a role in choosing the optimal tap position, i.e, it is used in a calculation of a pointer to an individual tap position $N_{t a p}(7)$. Voltage control from the lowest tap position $-\frac{n_{T C}-1}{2}$ towards the highest one $\frac{n_{T C}-1}{2}$ results in a gradual increase in the voltage, 
which is suitable for searching for an optimal tap position with the DE algorithm, as there are no local minima in the search space.

$$
\begin{gathered}
N_{\text {tap }}=\left\{-\frac{n_{T C}-1}{2}, \ldots, 0, \ldots, \frac{n_{T C}-1}{2}\right\} \\
N_{\text {tap }}=N_{\text {tap }}\left\{\left\lfloor x_{p, 3} \cdot n_{T C}\right\rfloor+1\right\}
\end{gathered}
$$

\subsection{Loading Models}

The behavior of the loads with respect to the supply voltage has a great impact on the operation of network elements [53]. Therefore, polynomial models of the active $P_{\text {load }, i}(8)$ and reactive power $Q_{\text {load }, i}(9)$ consumed in a node $i$ with voltage amplitude $V_{i}$ are utilized [54]. The pairs of coefficients for defining constant power, constant current, and constant impedance loading models are $\left(a_{0}, b_{0}\right),\left(a_{1}, b_{1}\right)$, and $\left(a_{2}, b_{2}\right)$, respectively. These coefficients represent the independence, linear dependency, and quadratic voltage dependency of active $P_{\text {load }, i}$ and reactive power $Q_{\text {load }, i}$ and correspond to the constant power, constant current, and constant impedance loading models, respectively. Each pair of coefficients describes the share of a single model in the whole polynomial model. Therefore, the sum of coefficients for active and reactive power has the value 1 , as given in (10) and (11).

$$
\begin{aligned}
P_{\text {load }, i}= & P_{\text {load }, i}\left(a_{0}+a_{1} V_{i}+a_{2} V_{i}^{2}\right) \\
Q_{\text {load }, i}= & Q_{\text {load }, i}\left(b_{0}+b_{1} V_{i}+b_{2} V_{i}^{2}\right) \\
& a_{0}+a_{1}+a_{2}=1 \\
& b_{0}+b_{1}+b_{2}=1
\end{aligned}
$$

\section{Test Site}

The following section presents an actual MV network model used in a case study of optimization of a network operation by utilizing active elements. The network considered within simulations in Section 4 was included in the Slovene-Japanese smart grid project NEDO and was equipped with the above standard devices, functionalities, and network observability. Although above standard, the measurement and communication infrastructure is still insufficient to provide the exact value of power losses in the network, since power generation and consumption data are not provided for all network users. Therefore, DN operation simulations are still used when discussing and assessing network losses since the required measurements cannot be performed. Furthermore, minimization of power losses was not the primary goal of the abovementioned project, and our paper analyzes how the newly installed active network elements could be used to improve additional aspects of network operation.

The single line diagram of the considered MV network presented in Figure 4 was used for the quasi steady-state analysis of the network operation. Three $20 \mathrm{kV}$ feeders were connected to the $110 / 20 \mathrm{kV}$ transformer substation supplying $110 \mathrm{MV} / \mathrm{LV}$ DSSs and 30 DG units. The total rated power of the generation units was $1.25 \mathrm{MW}$, composed of the $\mathrm{PV}$ systems and hydropower plants, in approximately the same share. Time-dependent loading conditions in the discussed network were determined from power loading and generation measurements for 5 July 2019, provided by the electric utility company. The network model is composed of 296 nodes and 297 branches, forming two loops. Loops can be opened or closed remotely by introducing relays with switching capability and bi-directional communication between them, at 14 points (referred to as breakpoints), in the considered part of the network. These elements enable the consideration of network configuration as an active element of the network. A schematic presentation of the considered network is given in Figure 5, with 14 remotely controlled breakpoints, i.e., relays with switching capabilities, marked by a red cross sign " $\times$ ". 


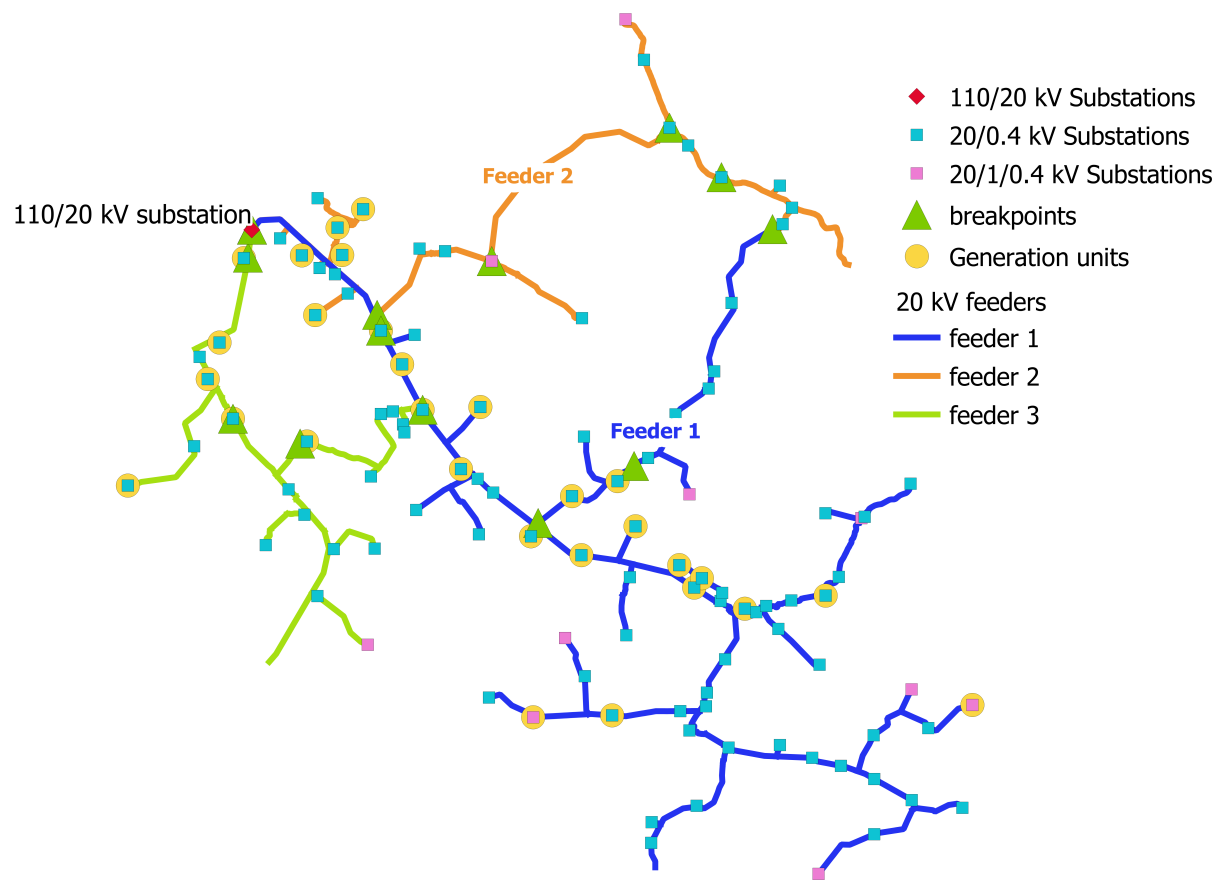

Figure 4. Single-line diagram of a test MV DN.

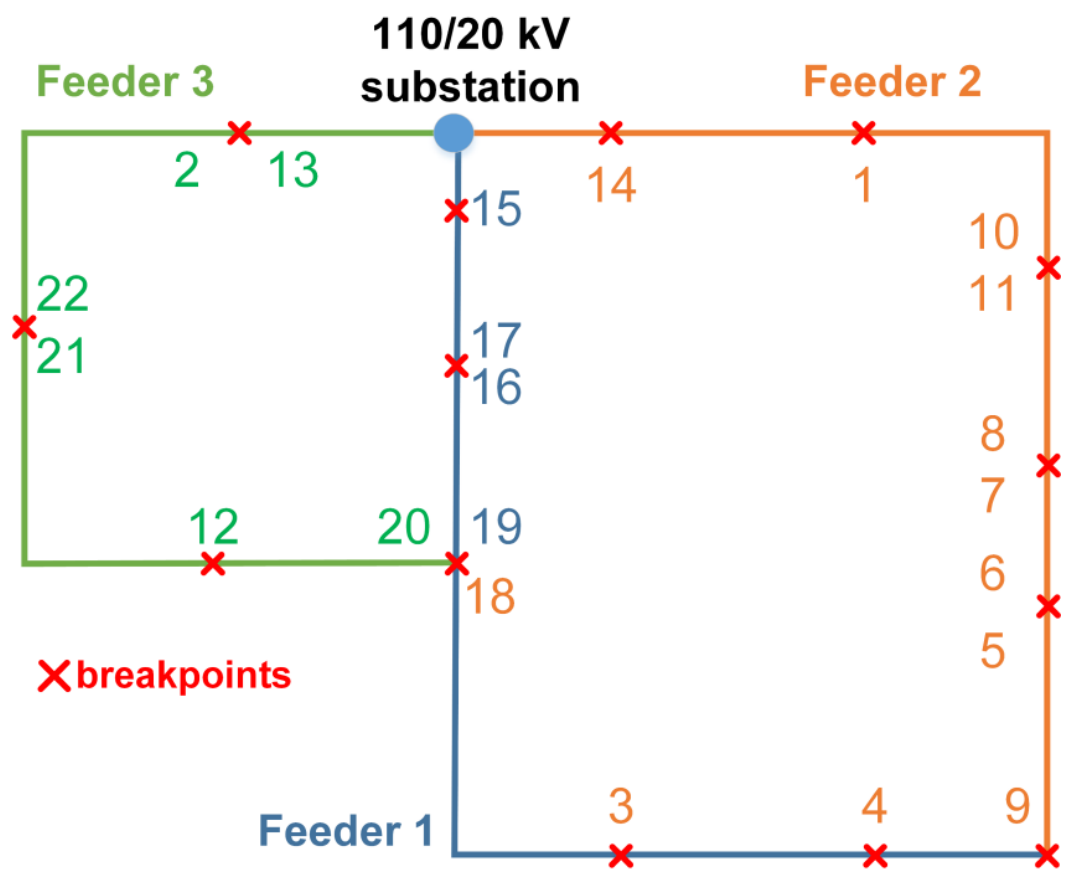

Figure 5. Schematic presentation of the locations of breakpoints in a test MV DN.

Numbers 1 to 22 in Figure 5 represent the indices of network configurations obtained by decoupling two feeders. Opening some breakpoints can result in two or three possible configurations, which is a result of the breakpoint being placed at the location of an MV/LV substation, allowing the substation to be supplied by different feeders. In order to achieve a radial configuration from the original meshed topology, two breakpoints from the sets $\boldsymbol{F}_{\mathbf{1}}$ (12) and $\boldsymbol{F}_{\mathbf{2}}$ (13) must be opened. The number of possible radial configurations $n_{C F}$ is then determined from the product of cardinalities of sets $\boldsymbol{F}_{1}$ and $\boldsymbol{F}_{2}$, marked $\left|\boldsymbol{F}_{1}\right|$ and $\left|\boldsymbol{F}_{2}\right|$, resulting in 72 possible radial configurations (14). 


$$
\begin{gathered}
\boldsymbol{F}_{1}=\{14,1,10,11,8,7,6,5,9,4,3,18\} \\
\boldsymbol{F}_{2}=\{13,2,22,21,12,20\} \\
n_{C F}=\left|\boldsymbol{F}_{1}\right|\left|\boldsymbol{F}_{2}\right|=12 \cdot 6=72
\end{gathered}
$$

However, a detailed analysis, including the simulations and measurements performed in the part of the network discussed during the NEDO project, has shown that the optimal radial configuration always included decoupling Feeder 1 and Feeder 3 at a breakpoint indexed 20. On the other hand, optimal decoupling of Feeder 1 and Feeder 2 was dependent on an operational point and had to be carefully chosen each time. Therefore, an assumption that decoupling Feeders 1 and 3 is independent of the operational point was made, reducing the number of possible combinations from 72 to 12. In order to find the pointer in an optimal network configuration $N_{C F}$ out of all of the vectors of possible radial configurations $N_{C F}$ utilized by decoupling Feeders 1 and 2 (15), the expression given in (4) is rewritten as (16).

$$
\begin{gathered}
N_{C F}=F_{1}=\{14,1,10,11,8,7,6,5,9,4,3,18\} \\
N_{C F}=N_{C F}\left\{\left\lfloor x_{p, 2} \cdot 12\right\rfloor+1\right\}
\end{gathered}
$$

The primary substation supplying the considered part of the network is equipped with an OLTC, which allows for voltage control in a range $\pm 16 \%$ of the rated voltage in $n_{T C}=25$ discrete steps with $1.33 \%$ per step, i.e., tap positions $\pm 12 \cdot 1.33 \%$. The amplitude of the voltage of the slack bus $V_{1}$ for the selected tap position $N_{\text {tap }}$ is determined by (17).

$$
V_{1}=V_{\text {base } M V}+N_{\text {tap }} \frac{1.33 \%}{100 \%} V_{\text {base } M V}
$$

where

$$
N_{\text {tap }}=\left\{-\frac{n_{\mathrm{TC}}-1}{2}, \ldots, 0, \ldots, \frac{n_{\mathrm{TC}}-1}{2}\right\}=\{-12,-11, \ldots, 0, \ldots, 11,12\},
$$

Thus, we rewrite (7) as (19).

$$
N_{\text {tap }}=N_{\text {tap }}\left\{\left\lfloor x_{\mathrm{p}, 3} \cdot 25\right\rfloor+1\right\}
$$

\section{Results}

Four simulation scenarios were conducted to evaluate the impact of individual and simultaneous considerations of an optimal reactive power generation by DG units, an optimal network reconfiguration, and an optimal OLTC operation on power losses. The following four cases were considered:

- Case 1: The impact of reactive power generation on power losses $x_{p}=\left\{x_{p, 1}\right\}$

- Case 2: The impact of network reconfiguration on power losses $x_{p}=\left\{x_{p, 2}\right\}$

- Case 3: The impact of OLTC operation on power losses $x_{p}=\left\{x_{p, 3}\right\}$

- Case 4: The impact of simultaneous consideration of all three active elements on power losses $x_{p}=\left\{x_{p, 1}, x_{p, 2}, x_{p, 3}\right\}$

The initial network operation is considered the one in which the network operates in a designed radial configuration (Feeders 1 and 2, and Feeders 1 and 3 decoupled as designed, i.e., in breakpoints with indices 9 and 20-see Figure 5) and with the tap position of OLTC set to $+3 \cdot 1.33 \%$. Reactive power generated by DG units in the network is determined from the available measurements. Power losses in a time-discrete operation state are first determined for the initial conditions $\left(P_{\text {loss }}\right.$ orig $)$, and then minimized through recalculation of power losses with altered active elements' settings $\left(P_{\text {loss }}\right)$ as given in (1). Loads in the network are represented using the constant power loading model (CPM) and constant impedance loading model (CIM). The results given herein are grouped into two subsections 
and evaluate the impact of active elements' optimal operations on a single, time-discrete point of operation and daily operation.

\subsection{Optimization of a Single Operation State}

Optimization of the time-discrete operation state for loading and generation conditions on 5 July 2019 at 9 a.m. is discussed in this subsection. The optimal settings of the considered active elements determined individually (Case 1, Case 2, and Case 3) or simultaneously (Case 4) are represented with variables $q(3), N_{C F}(16)$ and $N_{\text {tap }}(19)$ and are given in Table 1, together with the reductions in power loss achieved. The results are given for CPM for demonstration purposes, while the effect of load modeling on active elements' behavior is investigated in Section 4.2.

Table 1. Optimization of a single operation point for constant power loading model (CPM).

\begin{tabular}{lcccc}
\hline Optimization Results & Case 1 & Case 2 & Case 3 & Case 4 \\
\hline optimal search population $\boldsymbol{x}_{p}$ & $x_{p, 1}=1.000$ & $x_{p, 2}=0.805$ & $x_{p, 3}=0.789$ & $\boldsymbol{x}_{p}=\{1,0.789,0.790\}$ \\
optimal settings of active elements & $q=0.75$ & $N_{C F}=4$ & $N_{\text {tap }}=7$ & $q=0.75, N_{C F}=4, N_{\text {tap }}=7$ \\
reduction of power losses & $4.77 \%$ & $0.48 \%$ & $10.14 \%$ & $14.71 \%$ \\
\hline
\end{tabular}

The results given in Table 1 show that the individual roles of active elements in the minimization of power losses differ significantly. In Case 1, a reduction in power losses by $4.77 \%$ is achieved when DG units generate the maximum allowed amounts of reactive power of a capacitive nature. The compensation of reactive power flows in the network depends on network loading conditions, location, and active power generation by DG units that participate in the reactive power provision. In this case, DG units were insufficient to reverse active or reactive power flows. Thus, DG units were allowed to generate as much reactive power as possible.

A reduction in power losses by merely $0.48 \%$ is achieved when the breakpoint with index 4 neighboring the initially opened breakpoint indexed 9 is opened (see Figure 5). The original topology of the MV test site was well designed and already operated in nearoptimal configuration. The algorithm, however, determined that a slight change in the network configuration can reduce power losses.

By changing the tap position of OLTC from the initial $3 \cdot 1.33 \%$ to the optimal $7 \cdot 1.33 \%$, as determined in Case 3, the power losses are reduced by $10.14 \%$. Increasing the voltage level at a slack node increases the voltage profile throughout the whole network. When the loads are described using CPM, a reduction in power losses is achieved since higher voltages require smaller line currents. A proper voltage level is ensured using penalization functions, which prevent tap positions that cause violations of voltage constraints.

The last simulation scenario, i.e., Case 4, simultaneously determined the optimal settings of the active elements considered, and as expected, the reduction in power losses achieved was the highest (14.71\%).

\subsection{Optimization of a Daily Operation}

The procedure proposed in this paper is intended to be a tool for the optimization of a single operation state. However, if a series of time-discrete optimization procedures are performed for several consecutive time-discrete points, the energy losses in the considered interval are minimized. Therefore, 24 optimization procedures, representing every hour on 5 July 2019, were conducted to assess the daily reduction in energy losses that can be achieved. The reduction in energy losses achieved for four simulation scenarios, when considering CPM and CIM, is presented in Table 2. Furthermore, the distribution of hourly values of reduction in power losses for all considered cases is presented in Figure 6. The results show that simultaneous consideration of all active elements, as expected, yields the best results in terms of minimization of power and energy losses. By simultaneously determining the optimal operation of active elements, the maximum reduction in power 
losses in the considered network was $18.06 \%$ in the case of CPM and $27.49 \%$ in the case of CIM.

Table 2. Reduction in daily energy losses for different loading models.

\begin{tabular}{lcccc}
\hline & Case 1 & Case 2 & Case 3 & Case 4 \\
\hline reduction of daily energy losses (CPM) & $3.65 \%$ & $0.62 \%$ & $10.20 \%$ & $13.52 \%$ \\
reduction of daily energy losses (CIM) & $3.09 \%$ & $0.34 \%$ & $13.53 \%$ & $18.33 \%$ \\
\hline
\end{tabular}

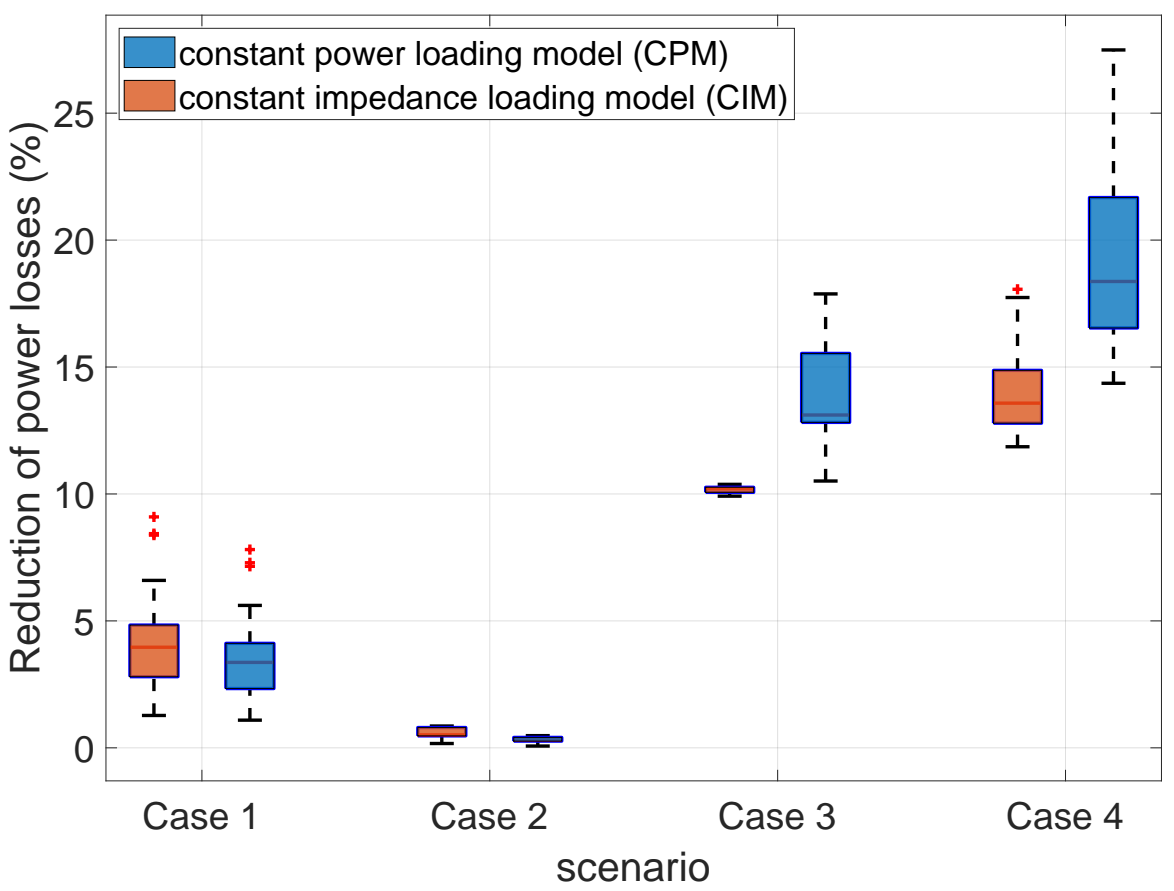

Figure 6. Distribution of hourly values of reduction in power losses.

Figure 7 utilizes the secondary $y$ axis to present the reactive power demand in the original network, when considering CPM and CIM, as well as the optimal reactive power generation, determined by the proposed algorithm (Case 1). Power losses were minimized at all considered points of operation and for both loading models, achieved when the search parameter had the value $x_{p, 1}=1$ (3). This value yields the maximum allowed reactive power generation, i.e., $75 \%$ of the active power generated. Even after increasing the reactive power generation to the highest allowed value, the reactive power demand could not be overcompensated. Therefore, the optimization algorithm always kept the reactive power generation as high as possible in both loading models. The reduction in power losses depends on the difference between the reactive power demand and generation at every considered point of operation. This difference was somewhat smaller during the early morning hours due to low consumption in the network and during the afternoon hours, when the active power generated by the DG systems increases, thus increasing the reactive power generation. These were the hours at which a more significant reduction in power losses was achieved. The reduction was smaller when the network loads were represented using CIM due to the increased total reactive power demand (compared to the CPM). Since the reactive power generation was the same for both CPM and CIM, the share of reactive power compensated was reduced in the case of CIM, thus increasing the power losses. 


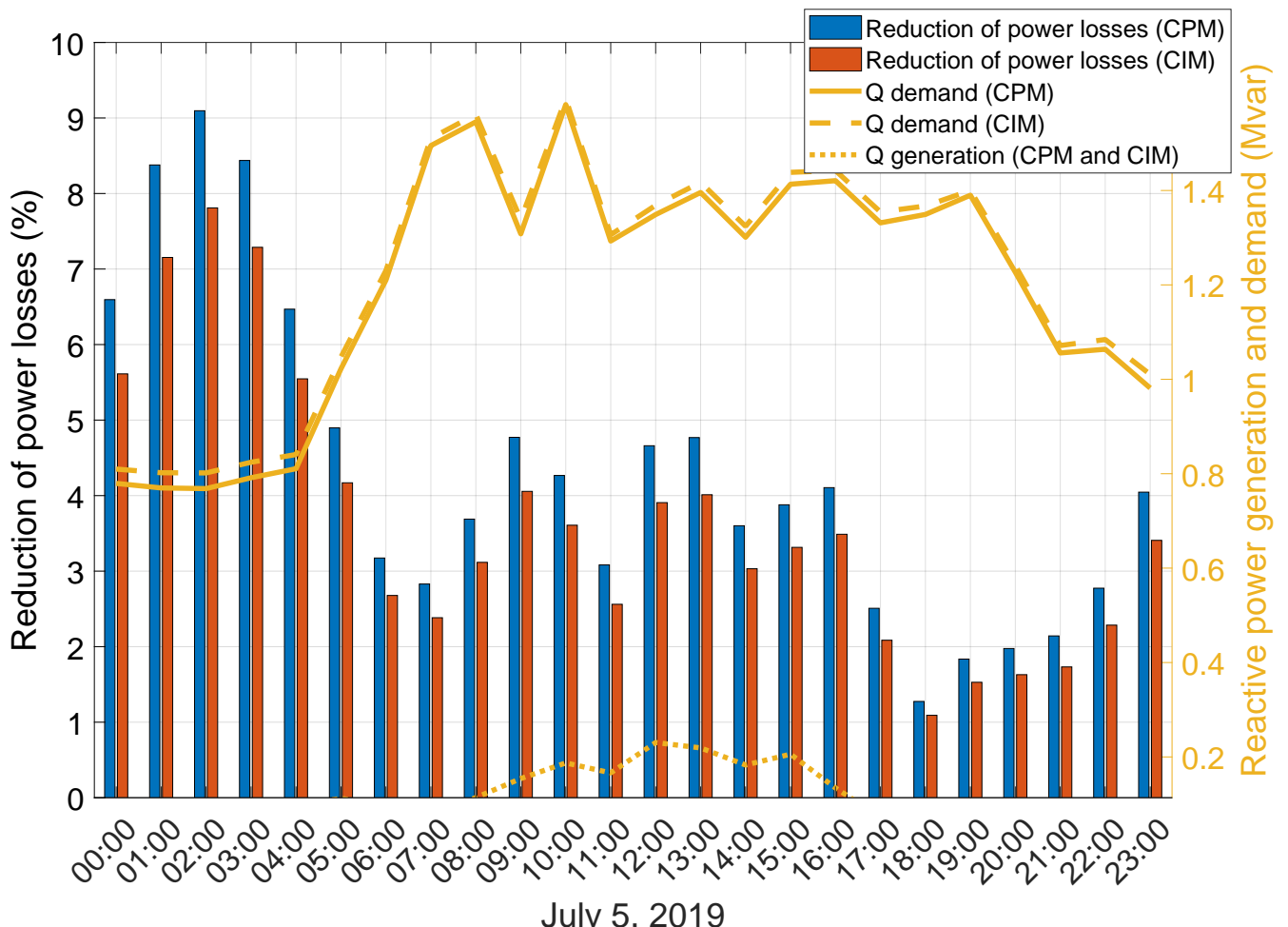

Figure 7. Reduction in power losses by optimal reactive power generation (Case 1).

The results for 5 July 2019 at 9 a.m. given in Table 1 showed that optimal active elements' settings were the same for their individual and simultaneous considerations. These values are not necessarily the same, as shown in Figures 8 and 9. The figures respectively illustrate the hourly values of opened breakpoint indices and optimal tap positions for Case 3 and Case 4. The figures present the results for CIM consideration, as tap positions in the CPM case are kept at the highest possible value (tap position $7 \cdot 1.33 \%$ ), and the difference is not as noticeable.

\begin{tabular}{|c|c|c|c|c|c|c|c|c|c|c|c|c|}
\hline hour & $00: 00$ & $01: 00$ & $02: 00$ & $03: 00$ & $04: 00$ & $05: 00$ & $06: 00$ & $07: 00$ & $08: 00$ & $09: 00$ & $10: 00$ & $11: 00$ \\
\hline$N_{\text {CF }}$ (Case 3) & 4 & 4 & 4 & 4 & 4 & 3 & 4 & 4 & 4 & 4 & 4 & 4 \\
\hline hour & $12: 00$ & $13: 00$ & $14: 00$ & $15: 00$ & $16: 00$ & $17: 00$ & $18: 00$ & $19: 00$ & $20: 00$ & $21: 00$ & $22: 00$ & $23: 00$ \\
\hline$N_{\text {CF }}$ (Case 3) $N_{\text {CF }}$ (Case 4) & 4 & 4 & 4 & 4 & 4 & 4 & 4 & 4 & 4 & 4 & 4 & 4 \\
\hline
\end{tabular}

Figure 8. Opened breakpoint indices for different simulation scenarios and constant impedance loading model (CIM). 


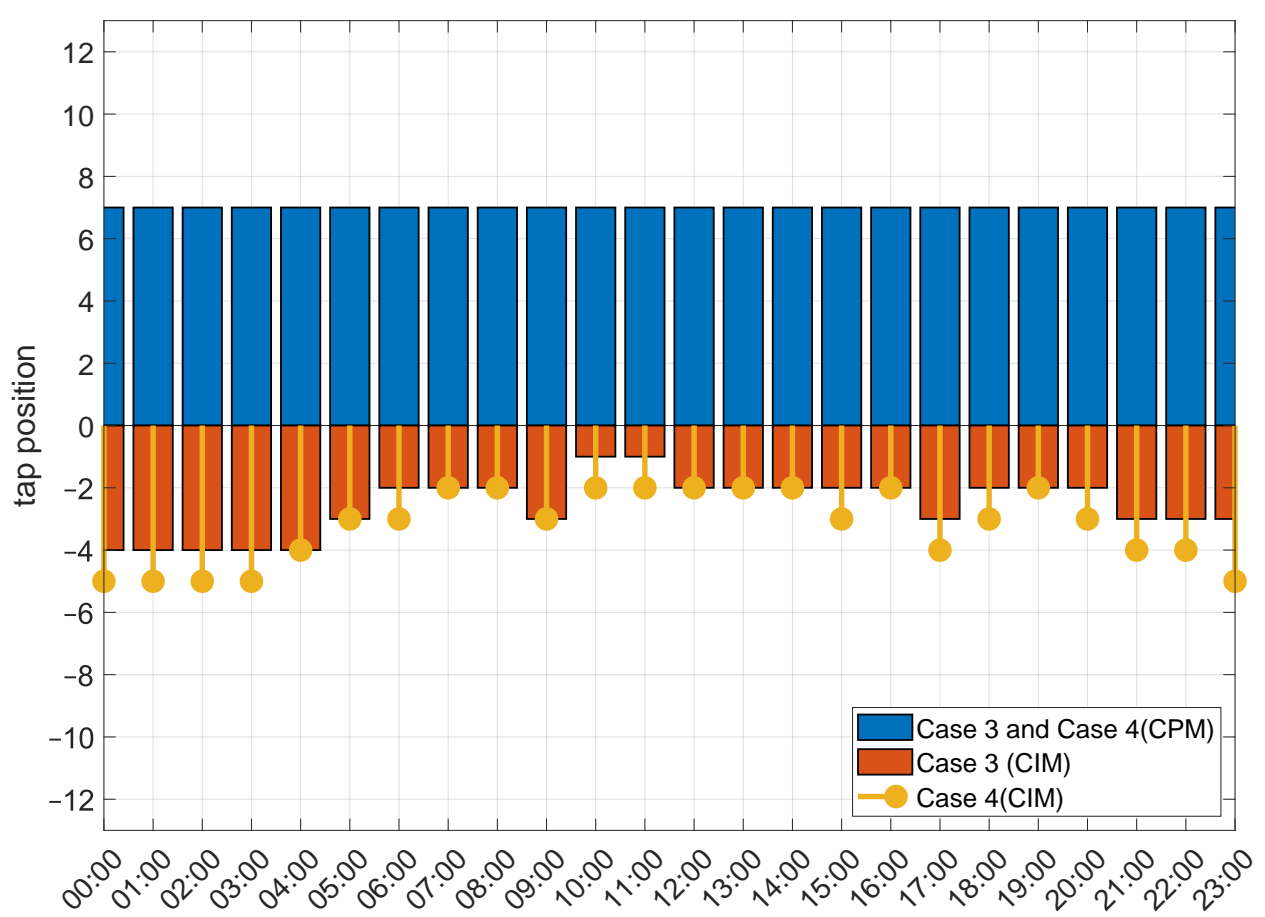

July 5, 2019

Figure 9. Optimal tap positions for different simulation scenarios and loading models.

\section{Conclusions}

The proliferated integration of active network elements and the measurement and communication infrastructure enable innovative approaches for evaluating and optimizing DN operations. This paper presents a straightforward and computationally efficient procedure that utilizes active elements to improve the technical aspects of a network operation, such as minimization of power losses while ensuring the proper ampacities and voltage profiles. The active elements considered within the paper are DG units, capable of reactive power provision; remotely controlled switches for changing the network configuration; and OLTC equipped substation, supplying the network. The proposed procedure is scalable and flexible and can include increased numbers and additional types of active elements. The novelties include simultaneous consideration of the aforementioned active elements for achieving minimization of power losses of a time-discrete operation state while ensuring voltage and current constraints. Furthermore, by performing a series of consecutive optimization producers on a given time interval, the optimization of a network operation for an extended period with arbitrarily time-discretization can be achieved.

Evaluation of the optimal participation of active elements, considered individually or simultaneously, on a network operation was analyzed on a real MV network model. The impact of a voltage profile on load behavior was also considered through two extreme cases, i.e., all loads in the network represented using the constant power or constant impedance loading model.

The results show that active participation of the DG units in local reactive power provision could be used to optimize network operation. The extent to which DG units can affect DN operation depends on their number, size, and location. Therefore, with the anticipation of an increased number of DG units, it is expected that their role in improving the voltage profile and in reducing power losses will also increase.

The network reconfiguration for a considered case study is the least efficient method for reducing power losses, yielding only up to $1 \%$ reduction. However, the results do not imply that network reconfiguration is an inappropriate measure but rather that the network was already designed well and that the radial configuration in which the network operates is almost the optimal one. The importance of time-dependent network reconfiguration will 
also increase with the integration of new network elements, increasing power demand, and the volatile nature of DG units.

OLTC is already a well-known tool for voltage control. However, if properly utilized, it can facilitate reductions in power losses as well. The optimal tap operation behavior depends significantly on the loading model used and points to the importance of proper modeling of network elements. Original daily energy losses in the constant impedance loading model are higher than in a constant power loading model due to the aforementioned voltage dependency. Additionally, the percentage of reduction achieved is higher since lowering the network voltage by lowering OLTC's tap position results in a reduction in the power consumption. Therefore, the load behavior as a function of network voltage should be permanently monitored and evaluated in network operation. This way, proper loading models required for determining optimal tap positions can be provided.

Utilization of the individually determined settings of the active elements should be avoided for optimization of the network operation. Even though each active element is set to optimize network operation in its way, the combination of individually determined parameters could yield suboptimal results, increased power flow in a network, or even violations of the voltage constraints. Therefore, calculating optimal operation of the active elements should be performed simultaneously to avoid such problems. Furthermore, simultaneous consideration of the active elements yielded a significant $27.5 \%$ reduction in power loss. Considering that the discussed active elements are already present in the network, implementation of the proposed algorithm represents a path towards reducing power consumption in the network, improving overall DN operation efficiency, and reducing $\mathrm{CO}_{2}$ emissions, provided proper communication of the measurement infrastructure. Further improvements in the reduction of power losses could be achieved by incorporating additional active elements. The procedure proposed in this paper is formulated to easily include these additional elements by adding new search parameters in the existing objective function.

Author Contributions: Conceptualization and validation: G.Š. and N.S.; data curation: M.R.; formal analysis, methodology, software, and writing —original draft: N.S.; writing — review and editing, and supervision: G.Š. All authors have read and agreed to the published version of the manuscript.

Funding: This work was supported in part by the Slovenian Research Agency under research contracts: 1000-19-0552, P2-0115 and J2-1742. The authors thank ELES d.o.o. for supporting our research in the scope of NEDO demonstration project, grant no. POG2017/0502.

Data Availability Statement: The data presented in this study are available on request from the corresponding author. The data are not publicly available since they belong to the electric utility company.

Conflicts of Interest: The authors declare no conflict of interest.

\section{Abbreviations}

The following abbreviations are used in this manuscript:

$\begin{array}{ll}\text { AMI } & \text { Advanced Measuring Infrastructure } \\ \text { CPM } & \text { Constant Power loading Model } \\ \text { CIM } & \text { Constant Impedance loading Model } \\ \text { DE } & \text { Differential Evolution } \\ \text { DG } & \text { Distributed Generation } \\ \text { DN } & \text { Distribution Network } \\ \text { DSS } & \text { Distribution SubStation } \\ \text { LV } & \text { Low Voltage } \\ \text { MV } & \text { Medium Voltage } \\ \text { OLTC } & \text { On-Load Tap Changer }\end{array}$




\section{References}

1. Hancher, L.; Talus, K.; Wüstenberg, M. Retrospective application of legal rules in the European Union: recent practice in the energy sector. J. Energy Nat. Resour. Law 2020, 39, 65-81. [CrossRef]

2. Directorate-General for Energy (European Commission). Clean Energy for All Europeans; Publications Office of the European Union: Luxembourg, 2019. [CrossRef]

3. Ehsan, A.; Yang, Q. State-of-the-art techniques for modelling of uncertainties in active distribution network planning: A review. Appl. Energy 2019, 239, 1509-1523. [CrossRef]

4. Jordehi, A.R. Optimisation of electric distribution systems: A review. Renew. Sustain. Energy Rev. 2015, 51, 1088-1100. [CrossRef]

5. Sedghi, M.; Ahmadian, A.; Aliakbar-Golkar, M. Assessment of optimization algorithms capability in distribution network planning: Review, comparison and modification techniques. Renew. Sustain. Energy Rev. 2016, 66, 415-434. [CrossRef]

6. Crawford, D.M.; Holt, S.B. A mathematical optimization technique for locating and sizing distribution substations, and deriving their optimal service areas. IEEE Trans. Power Appar. Syst. 1975, 94, 230-235. [CrossRef]

7. Wall, D.L.; Thompson, G.L.; Northcote-Green, J. An Optimization Model for Planning Radial Distribution Networks. IEEE Trans. Power Appar. Syst. 1979, PAS-98, 1061-1068. [CrossRef]

8. Resener, M.; Haffner, S.; Pereira, L.A.; Pardalos, P.M. Optimization techniques applied to planning of electric power distribution systems: A bibliographic survey. Energy Syst. 2018, 9, 473-509. [CrossRef]

9. Kalambe, S.; Agnihotri, G. Loss minimization techniques used in distribution network: Bibliographical survey. Renew. Sustain. Energy Rev. 2014, 29, 184-200. [CrossRef]

10. Chang, H.C.; Kuo, C.C. Network reconfiguration in distribution systems using simulated annealing. Electr. Power Syst. Res. 1994, 29, 227-238. [CrossRef]

11. Skoonpong, A.; Sirisumrannukul, S. Network reconfiguration for reliability worth enhancement in distribution systems by simulated annealing. In Proceedings of the 2008 5th International Conference on Electrical Engineering/Electronics, Computer, Telecommunications and Information Technology, Krabi, Thailand, 14-17 May 2008; Volume 2, pp. 937-940.

12. AlRashidi, M.R.; El-Hawary, M.E. A Survey of Particle Swarm Optimization Applications in Electric Power Systems. IEEE Trans. Evol. Comput. 2009, 13, 913-918. [CrossRef]

13. Gupta, N.; Swarnkar, A.; Niazi, K. Reconfiguration of distribution systems for real power loss minimization using adaptive particle swarm optimization. Electr. Power Compon. Syst. 2011, 39, 317-330. [CrossRef]

14. Mahboubi-Moghaddam, E.; Narimani, M.R.; Khooban, M.H.; Azizivahed, A.; Sharifi, M.J. Multi-objective distribution feeder reconfiguration to improve transient stability, and minimize power loss and operation cost using an enhanced evolutionary algorithm at the presence of distributed generations. Int. J. Electr. Power Energy Syst. 2016, 76, 35-43. [CrossRef]

15. Hamida, I.B.; Salah, S.B.; Msahli, F.; Mimouni, M.F. Simultaneous Distribution Network Reconfiguration and Optimal Distributed Generations Integration using a Pareto Evolutionary Algorithm. Int. J. Renew. Energy Res. 2018, 8, 345-356.

16. Duan, D.L.; Ling, X.D.; Wu, X.Y.; Zhong, B. Reconfiguration of distribution network for loss reduction and reliability improvement based on an enhanced genetic algorithm. Int. J. Electr. Power Energy Syst. 2015, 64, 88-95. [CrossRef]

17. Agrawal, P.; Kanwar, N.; Gupta, N.; Niazi, K.R.; Swarnkar, A.; Meena, N.K.; Yang, J. Reliability and Network Performance Enhancement by Reconfiguring Underground Distribution Systems. Energies 2020, 13, 4719. [CrossRef]

18. Salazar, H.; Gallego, R.; Romero, R. Artificial neural networks and clustering techniques applied in the reconfiguration of distribution systems. IEEE Trans. Power Deliv. 2006, 21, 1735-1742. [CrossRef]

19. Fathabadi, H. Power distribution network reconfiguration for power loss minimization using novel dynamic fuzzy c-means (dFCM) clustering based ANN approach. Int. J. Electr. Power Energy Syst. 2016, 78, 96-107. [CrossRef]

20. Sultana, B.; Mustafa, M.; Sultana, U.; Bhatti, A.R. Review on reliability improvement and power loss reduction in distribution system via network reconfiguration. Renew. Sustain. Energy Rev. 2016, 66, 297-310. [CrossRef]

21. Celli, G.; Pilo, F.; Pisano, G.; Allegranza, V.; Cicoria, R.; Iaria, A. Meshed vs. radial MV distribution network in presence of large amount of DG. In Proceedings of the IEEE PES Power Systems Conference and Exposition, New York, NY, USA, 10-13 October 2004; pp. 709-714.

22. Dorostkar-Ghamsari, M.R.; Fotuhi-Firuzabad, M.; Lehtonen, M.; Safdarian, A. Value of distribution network reconfiguration in presence of renewable energy resources. IEEE Trans. Power Syst. 2015, 31, 1879-1888. [CrossRef]

23. Lopez, E.; Opazo, H.; Garcia, L.; Bastard, P. Online reconfiguration considering variability demand: Applications to real networks. IEEE Trans. Power Syst. 2004, 19, 549-553. [CrossRef]

24. Esmaeili, S.; Anvari-Moghaddam, A.; Jadid, S.; Guerrero, J.M. Optimal simultaneous day-ahead scheduling and hourly reconfiguration of distribution systems considering responsive loads. Int. J. Electr. Power Energy Syst. 2019, 104, 537-548. [CrossRef]

25. Zidan, A.; El-Saadany, E. Network reconfiguration in balanced and unbalanced distribution systems with variable load demand for loss reduction and service restoration. In Proceedings of the 2012 IEEE Power and Energy Society General Meeting, San Diego, CA, USA, 22-26 July 2012; pp. 1-8.

26. Fajardo, O.F.; Vargas, A. Reconfiguration of MV distribution networks with multicost and multipoint alternative supply, part I: Economic dispatch through radialization. IEEE Trans. Power Syst. 2008, 23, 1393-1400. [CrossRef] 
27. Srećković, N.; Štumberger, G. The Impact of Photovoltaic Systems on Power losses and voltage profiles in a real medium voltage distribution network. In Proceedings of the V: International Conference on Renewable Energies and Power Quality (ICREPQ'15), La Coruña, Spain, 25-27 March 2015; pp. 25-27.

28. Acosta, M.N.; Gonzalez-Longatt, F.; Topić, D.; Andrade, M.A. Optimal Microgrid-Interactive Reactive Power Management for Day-Ahead Operation. Energies 2021, 14, 1275. [CrossRef]

29. Vlahinić, S.; Franković, D.; Komen, V.; Antonić, A. Reactive Power Compensation with PV Inverters for System Loss Reduction. Energies 2019, 12, 4062. [CrossRef]

30. Gandhi, O.; Rodríguez-Gallegos, C.D.; Zhang, W.; Srinivasan, D.; Reindl, T. Economic and technical analysis of reactive power provision from distributed energy resources in microgrids. Appl. Energy 2018, 210, 827-841. [CrossRef]

31. Sukič, P.; Belič, E.; Trbušić, M.; Štumberger, G. The impact of reactive power generation in PV systems on their yearly production of electrical energy. In Proceedings of the ICREPQ'16-International Conference on Renewable Energies and Power Quality (ICREPQ'16), Madrid, Spain, 4-6 May 2016.

32. Dohnal, D. On-Load Tap Changers for Power Transformers; Maschinenfabrik Reinhausen GmbH: Regensburg, Germany, 2013.

33. Gao, C.; Redfern, M.A. A review of voltage control techniques of networks with distributed generations using On-Load Tap Changer transformers. In Proceedings of the 45th International Universities Power Engineering Conference UPEC2010, Cardiff, UK, 31 August-3 September 2010; pp. 1-6.

34. Ge, X.; Shen, L.; Zheng, C.; Li, P.; Dou, X. A Decoupling Rolling Multi-Period Power and Voltage Optimization Strategy in Active Distribution Networks. Energies 2020, 13, 5789. [CrossRef]

35. Maknouninejad, A.; Qu, Z. Realizing unified microgrid voltage profile and loss minimization: A cooperative distributed optimization and control approach. IEEE Trans. Smart Grid 2014, 5, 1621-1630. [CrossRef]

36. Kryonidis, G.C.; Demoulias, C.S.; Papagiannis, G.K. A nearly decentralized voltage regulation algorithm for loss minimization in radial MV networks with high DG penetration. IEEE Trans. Sustain. Energy 2016, 7, 1430-1439. [CrossRef]

37. Kolenc, M.; Papič, I.; Blažič, B. Minimization of losses in smart grids using coordinated voltage control. Energies 2012, 5, 3768-3787. [CrossRef]

38. Zhang, Y.j.; Ren, Z. Optimal reactive power dispatch considering costs of adjusting the control devices. IEEE Trans. Power Syst. 2005, 20, 1349-1356. [CrossRef]

39. Storn, R.; Price, K. Differential Evolution-A Simple and Efficient Heuristic for global Optimization over Continuous Spaces. J. Glob. Optim. 1997, 11, 341-359. [CrossRef]

40. EN 50160:2011. Voltage Characteristics of Electricity Supplied by Public Distribution Networks; CENELEC: Brussels, Belgium, 2011.

41. Bai, L.; Jiang, T.; Li, F.; Chen, H.; Li, X. Distributed energy storage planning in soft open point based active distribution networks incorporating network reconfiguration and DG reactive power capability. Appl. Energy 2018, 210, 1082-1091. [CrossRef]

42. Hebin, R.; Hongjun, G.; Junyong, L.; Youbo, L. A Distributionally Robust Reactive Power Optimization Model for Active Distribution Network Considering Reactive Power Support of DG and Switch Reconfiguration. Energy Procedia 2019, 158, 6358-6365. [CrossRef]

43. Thukaram, D.; Wijekoon Banda, H.M.; Jerome, J. A robust three phase power flow algorithm for radial distribution systems. Electr. Power Syst. Res. 1999, 50, 227-236. [CrossRef]

44. Pampara, G.; Engelbrecht, A.P.; Franken, N. Binary Differential Evolution. In Proceedings of the 2006 IEEE International Conference on Evolutionary Computation, Vancouver, BC, Canada, 16-21 July 2006; pp. 1873-1879. [CrossRef]

45. Li, T.; Dong, H.; Sun, J. Binary Differential Evolution Based on Individual Entropy for Feature Subset Optimization. IEEE Access 2019, 7, 24109-24121. [CrossRef]

46. Engelbrecht, A.P.; Pampara, G. Binary differential evolution strategies. In Proceedings of the 2007 IEEE Congress on Evolutionary Computation, Singapore, 25-28 September 2007; pp. 1942-1947. [CrossRef]

47. Deng, C.; Zhao, B.; Yang, Y.; Deng, A. Integer Encoding Differential Evolution Algorithm for Integer Programming. In Proceedings of the 2010 2nd International Conference on Information Engineering and Computer Science, Wuhan, China, 25-26 December 2010; pp. 1-4. [CrossRef]

48. Guo, Q.; Tang, L. Modelling and discrete differential evolution algorithm for order rescheduling problem in steel industry. Comput. Ind. Eng. 2019, 130, 586-596. [CrossRef]

49. Brecl, K.; Topič, M. Energy and Economic Yield of Photovoltaic Systems: Reactive-Power Impact. Elektrotehniški Vestnik 2014, $81,9$.

50. Yaprakdal, F.; Baysal, M.; Anvari-Moghaddam, A. Optimal Operational Scheduling of Reconfigurable Microgrids in Presence of Renewable Energy Sources. Energies 2019, 12, 1858. [CrossRef]

51. Thakar, S.; Vijay, A.S.; Doolla, S. System reconfiguration in microgrids. Sustain. Energy Grids Netw. 2019, 17, 100191. [CrossRef]

52. Liu, X.; Aichhorn, A.; Liu, L.; Li, H. Coordinated control of distributed energy storage system with tap changer transformers for voltage rise mitigation under high photovoltaic penetration. IEEE Trans. Smart Grid 2012, 3, 897-906. [CrossRef]

53. Arif, A.; Wang, Z.; Wang, J.; Mather, B.; Bashualdo, H.; Zhao, D. Load Modeling-A Review. IEEE Trans. Smart Grid 2018, 9, 5986-5999. [CrossRef]

54. Kersting, W.H. Distribution System Modeling and Analysis; CRC Press LLC: Boca Raton, FL, USA, 2002. 